\section{Events are bringing change to US Antarctic research}

\begin{abstract}
Washington. The US Antarctic Program, striving for balance between scientific exploration and environmental protection, may be headed down a new path that would greatly affect research on the continent.
\end{abstract}

In anticipation of a higher profile for the $\$ 240$-million a year programme, the National Science Foundation (NSF) has elevated its status from a division within the geosciences directorate to a programme within the office of the NSF director. Cornelius Sullivan, an oceanographer at the University of Southern California, has just been named to head the office, succeeding Peter Wilkness, who is stepping down after eight years (see below). At the same time, the US National Academy of Sciences is preparing a report for the State Department analysing the impact on science of a new international agreement on the environment, the end of the Cold War and growing interest in global climate.

Not surprisingly, all of these changes have made scientists apprehensive about their status. "Antarctica has always been considered a great big playground for scientists", says Susan Soloand a government scientist who studies ozone depletion over Antarctica. "But we've learned that we' $d$ better not throw any more candy wrappers on the ground."

The immediate concern is the pending interpretation of an international environmon, a member of the academy committee mental protocol adopted in October 1991 by the 26 countries with significant Antarctic research programmes. Although the US Senate approved the protocol last autumn, the State Department has decided that legislation is needed to spell out how its provisions

\section{IMAGE UNAVAILABLE FOR COPYRIGHT REASONS}

\section{Human and animal life share tight quarters.}

should be enforced.

A major question to be decided is the choice of an agency to regulate and monitor activity on the continent. The Bush administration last year supported a bill that would leave NSF in charge, but environmental groups favour giving regulatory authority to such agencies as the National Oceanic and Atmospheric Administration and the Envi-

\section{Spreading the word}

As an oceanographer with 13 expeditions to Antarctica and five to the Arctic, Comelius (Neil) Sullivan thinks that he understands what it means to do research at both poles. But applying that knowledge to fund the best science is only half of his new job as

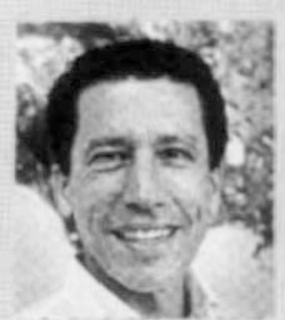

Neil Sullivan head of the Office of Polar Programs for the US National Science Foundation (NSF).

"We [scientists] need to present a much better picture to the US public of how polar science affects their lives", says Sullivan, who directs the Hancock Institute for Marine Studies at the University of Southern California. "The New Zealanders, for example, have a fine appreciation of Antarctica and what it means to them, and we need to send a similar message to students, to our colleagues and to Congress."

Sullivan says that increased concern about such environ mental issues as global warming and the ozone hole has created a receptive audience for his message. But greater visibility is a mixed blessing: "Being in the director's office means that any successes are noticed", he says. "But of course, there's an obvious downside to that."

At the age of 49 , Sullivan is prepared to work for half a dozen years or more to make an impact on the $\$ 240$-million programme. "It'll be two years before you can even see my fingerprints on the budget", he says, "and in any large organization, it takes quite a while to really do something. But I know I'II never be bored." J.M. ronmental Protection Agency.

Testifying on 23 February before the science subcommittee in the House of Representatives, NSF officials argued that the agency has the necessary expertise to do both science and environmental protection and that it is more efficient to let one agency coordinate both activities. But environmental groups say that NSF has had a sorry record of stewardship over the past 35 years and that there is an inherent conflict in an agency carrying out research and then certifying that its actions are legal.

Antarctic researchers are especially fearful of administrative obstacles that may delay or cancel experiments, including changes that might prevent them from responding quickly to scientific opportunities or regulations that could prohibit current activities.

A bill (HR 964) that takes NSF's side on most issues is sponsored by Representative Rick Boucher (Democrat, Virginia), chairman of the subcommittee that conducted the hearing. The Clinton administration has yet to take a position, although an interagency task force is expected to reach a decision by the summer.

At the same time as NSF is fighting to retain control of US activities in Antarctica, it is negotiating with the US Navy over the military's desire to reduce or eliminate its historic role of providing logistical support in Antarctica. The end of the Cold War and the decline in the US military budget is forcing the Defense Department to reexamine its presence, say Navy officials, and its 780 personnel may be needed elsewhere. The Navy has already convinced NSF to take over disposal of hazardous waste; starting on 1 October, a civilian company will perform those duties. In another change, US research institutions will be forced to dispose of lowlevel radioactive wastes generated by their scientists while working in Antarctica.

The US State Department is also interested in taking a fresh look at the Antarctic programme. The department has asked the National Academy of Sciences to report in June on the impact on science of the changing geopolitical climate and the increasing global concern about environmental issues.

National sovereignty has long been an important consideration in Antarctic exploration and State Department officials believe that research agendas will continue to be shaped by the desire of individual nations to maintain a presence. At the same time, Antarctica may hold the answers to important climatic questions.

"Tensions over the relationship between science and government policies are not new", Tucker Sculley, a State Department official, told the academy committee at a meeting last month. "But we have new players and new circumstances. And that puts a greater burden on scientists to be clear about their contribution."

Jeffrey Mervis 